\title{
Kinetics and Characterization of Degradation Products of Dihydralazine and Hydrochlorothiazide in Binary Mixture by HPLC- UV, LC-DAD and LC-MS Methods
}

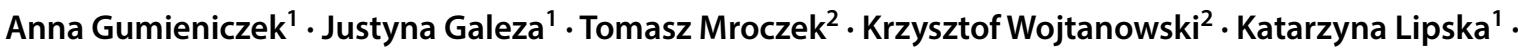 \\ Rafał Pietras ${ }^{1}$
}

Received: 30 March 2018 / Revised: 7 June 2018 / Accepted: 11 June 2018 / Published online: 25 June 2018

(c) The Author(s) 2018

\begin{abstract}
Dihydralazine and hydrochlorothiazide were stored at high temperature and humidity, under UV/Vis light and different $\mathrm{pH}$, as individual drugs and the mixture. Then, a sensitive and selective HPLC-UV method was developed for simultaneous determination of dihydralazine and hydrochlorothiazide in presence of their degradation products. Finally, the degradation products were characterized through LC-DAD and LC-MS methods. Dihydralazine was sensitive to high temperature and humidity, $\mathrm{UV} / \mathrm{Vis}$ light and $\mathrm{pH} \geq 7$. At the same time, it was resistant to acidic conditions. Hydrochlorothiazide was sensitive to high temperature and humidity, UV/Vis light and changes in $\mathrm{pH}$. Its highest level of degradation was observed in $1 \mathrm{M} \mathrm{HCl}$. Degradation of the drugs was higher when they were stressed in the mixture. In the case of dihydralazine, the percentage degradation was 5-15 times higher. What is more, dihydralazine became sensitive to acidic conditions. Hydrochlorothiazide was shown to be more sensitive to UV/Vis light and $\mathrm{pH}>4$. Degradation of dihydralazine and hydrochlorothiazide followed first-order kinetics. The quickest degradation of dihydralazine was found to be in $1 \mathrm{M} \mathrm{NaOH}$ while of hydrochlorothiazide was in $1 \mathrm{M} \mathrm{HCl}$ (individual hydrochlorothiazide) or at $\mathrm{pH}$ 7-10 (hydrochlorothiazide in the mixture). A number of new degradation products were detected and some of them were identified by our LC-DAD and LC-MS methods. In the stressed individual samples, (phenylmethyl)hydrazine and 1,2,4-benzothiadiazine-7-sulfonamide 1,1-dioxide were observed for the first time. Interactions between dihydralazine and hydrochlorothiazide in the mixture were confirmed by additional degradation products, e.g., 2H-1,2,4-benzothiadiazine-7-sulfonamide 1,1,4-trioxide.
\end{abstract}

Keywords Dihydralazine and hydrochlorothiazide $\cdot$ Kinetics of degradation · Degradation products · Interactions · HPLC-UV, LC-DAD and LC-MS methods

\section{Introduction}

Hydralazine and its derivative dihydralazine are used in the treatment of hypertension in Europe, the USA and China [1]. Because of their special action in some types of hypertension, they are included in European Pharmacopoeia (Eur. Ph.) [2]. They both are arterial vasodilators that can

Anna Gumieniczek

anna.gumieniczek@umlub.pl

1 Department of Medicinal Chemistry, Medical University of Lublin, Jaczewskiego 4, 20-090 Lublin, Poland

2 Department of Pharmacognosy with Medicinal Plant Unit, Medical University of Lublin, Chodźki 1, 20-093 Lublin, Poland reduce the resistance in arterial vessels. Because of this unique mechanism of action, they can be combined with other drugs of complementary effects, e.g., with hydrochlorothiazide from diuretics. Two-component formulations of hydralazine and hydrochlorothiazide are already present in the USA and China.

Although two-component tablets present many advantages, they introduce the problem of interactions between the active ingredients. For example, degradation of one drug may be accelerated by another one. Interactions can also lead to generate new degradation products. Therefore, the main goal of the present study was to examine stability of dihydralazine and hydrochlorothiazide, as individuals and in the mixture, to detect such interactions using HPLC-UV, LC-DAD and LC-MS methods. 
Only few chromatographic procedures (HPLC) have been reported so far for determination of dihydralazine alone [3] or in presence of other drugs like hydrochlorothiazide, triamteren and clonidine $[4,5]$. In the study of Raul et al. [3], dihydralazine was determined on a C18 column with a mobile phase consisted of phosphate buffer of $\mathrm{pH}$ 3.0 and acetonitrile, and UV detection at $305 \mathrm{~nm}$. However, there is no any report concerning forced degradation of dihydralazine. In consequence, kinetics of degradation as well as characterization of degradation products were not reported at all.

More HPLC methods were elaborated for determination of hydrochlorothiazide as an individual analyte $[6,7]$ or in presence of other drugs like sartans [8-10], angiotensin-converting enzyme inhibitors [11-13], beta blockers [14-16] and calcium channel blockers [17, 18]. Some HPLC methods were described as stability-indicating procedures capable to determine hydrochlorothiazide in presence of its degradation products [19-26].

In the study of Che [4], determination of dihydralazine and hydrochlorothiazide was performed using a $\mathrm{CN}$ column, while a mobile phase consisted of acetonitrile and sodium heptane sulphonate. Two different wavelengths were used for UV detection, i.e., 310 and $267 \mathrm{~nm}$, for dihydralazine and hydrochlorothiazide, respectively. Simultaneous determination of dihydralazine and hydrochlorothiazide was elaborated by Jin et al. [5] using gradient elution on a C18 column. Acetonitrile and phosphate buffer of $\mathrm{pH} 3.0$ containing sodium heptane sulphonate were used as mobile phases A and B, respectively. From these reports, it was clearly seen that simultaneous determination of these two drugs presenting different chemical properties, could be a big analytical challenge.

Stability of hydrochlorothiazide in a solid state was tested at high temperature in the range $60-110{ }^{\circ} \mathrm{C}[19,20,22-25$, 27]. As far as photostability is concerned, experiments were conducted at one wavelength (254 or $256 \mathrm{~nm}$ ) [20, 24, 25] or in the entire UV range [24, 28-30]. They were carried out in a solid state $[20,22,24,28,31]$ and less frequently in solutions $[25,29,30]$. Stability of hydrochlorothiazide was studied in $1 \mathrm{M} \mathrm{HCl}$ [19-22, 25, 30-32], $5 \mathrm{M} \mathrm{HCl}$ [28], $1 \mathrm{M} \mathrm{NaOH}$ [19-22, 25, 27, 31-37], $5 \mathrm{M} \mathrm{NaOH}$ [28], buffers [23] and methanol [19, 25]. One study on degradation of hydrochlorothiazide by LC/MS method was reported in the literature [27]. However, kinetics of degradation was studied incidentally and only scarce information in this area was found in the literature [23].

Thus, a new quantitative HPLC method for simultaneous determination of dihydralazine and hydrochlorothiazide in presence of their degradation products was elaborated and validated. Then, the concentration of non-degraded dihydralazine and hydrochlorothiazide as a function of degradation time was investigated, to determine kinetics of degradation. The next step was to elucidate the possible degradation pattern of these drugs using LC-DAD and LC-MS methods.

The results reported here can be useful in development of a new combined formulation of dihydralazine and hydrochlorothiazide, by knowing dangerous conditions for both constituents. In addition, these data may be the starting point for further studies on new degradation products in terms of their potential toxicity.

\section{Experimental}

\section{Materials and Methods}

\section{Materials}

Pharmaceutical grade (Eur. Ph.) dihydralazine sulfate and hydrochlorothiazide, and tetrabutylammonium hydrogen sulfate for analysis from Sigma-Aldrich (St. Louis, MO, USA), ammonium formate, formic acid, acetonitrile and methanol for LC from Merck (Darmstadt, Germany), acetic acid $\left(\mathrm{CH}_{3} \mathrm{COOH}\right)$, sodium acetate $\left(\mathrm{CH}_{3} \mathrm{COONa}\right)$, hydrochloric acid, sodium chloride $(\mathrm{NaCl})$, sodium tetraborate $\left(\mathrm{Na}_{2} \mathrm{~B}_{4} \mathrm{O}_{7}\right)$, sulphuric acid, sodium hydrogen phosphate $\left(\mathrm{NaHPO}_{4}\right)$, sodium hydroxide $(\mathrm{NaOH})$, kalium dihydrogen phosphate $\left(\mathrm{KH}_{2} \mathrm{PO}_{4}\right)$ and kalium hydroxide for analysis from POCh (Gliwice, Poland), acetonitrile and water for LC-MS from J.T. Baker (Center Valley, PA, USA), Dihydralazinum ${ }^{\circledR}$ tablets $25 \mathrm{mg}$ from Pabianickie Zakłady Farmaceutyczne (Pabianice, Poland) and Hydrochlorothiazidum ${ }^{\circledR}$ tablets $25 \mathrm{mg}$ from Polpharma (Starogard Gdanski, Poland) were used. Acetate buffer was prepared with $0.2 \mathrm{M} \mathrm{CH}_{3} \mathrm{COOH}$ and $0.2 \mathrm{M} \mathrm{CH}_{3} \mathrm{COONa}$. Phosphate buffer was prepared with $0.067 \mathrm{M} \mathrm{KH}_{2} \mathrm{PO}_{4}$ and $0.067 \mathrm{M} \mathrm{Na}_{2} \mathrm{HPO}_{4}$. Borate buffer was prepared with $0.05 \mathrm{M} \mathrm{Na}_{2} \mathrm{~B}_{4} \mathrm{O}_{7}$ and $0.1 \mathrm{M} \mathrm{NaOH}$. Buffers were prepared as described in Eur. Ph [2]. Buffers for kinetic studies have the same ionic strength of $1 \mathrm{M}$ which was attained with $4 \mathrm{M} \mathrm{NaCl}$. The $\mathrm{pH}$ measurements were done with a pH-meter HI9024C from Hanna Instruments (Padova, Italy).

\section{HPLC-UV Method}

\section{Chromatographic Conditions}

Analysis was performed with a model 306 pump with a loop Rheodyne $(20 \mu \mathrm{L})$ and a model UV170 detector controlled by Omnic software from Gilson (Middleton, WI, USA). Separation was carried out on a LiChrospher ${ }^{\circledR} \mathrm{CN}$ column $(125 \times 4.0 \mathrm{~mm}, 5 \mu \mathrm{m})$ from Merck. The column was housed in a column heater set at $25^{\circ} \mathrm{C}$. The mobile phase consisted of water, $0.02 \mathrm{M}$ tetrabutylammonium hydrogen sulfate 
and acetonitrile (20:65:15, v/v/v) adjusted to $\mathrm{pH} 3.5$ with $0.5 \mathrm{M}$ sulphuric acid. The flow rate of the mobile phase was $1.4 \mathrm{ml} \mathrm{mL}^{-1}$ while the detection was done at $235 \mathrm{~nm}$.

\section{Robustness}

Small changes of analytical conditions, i.e., acetonitrile content in a mobile phase $(15 \pm 2), \mathrm{pH}(3.5 \pm 0.1$ unit), flow rate of the mobile phase $\left(1.4 \pm 0.2 \mathrm{ml} \mathrm{mL}^{-1}\right)$, detection wavelength $(235 \pm 3 \mathrm{~nm})$ and column temperature $\left(25 \pm 2{ }^{\circ} \mathrm{C}\right)$ were made to study robustness of the developed method. One factor was changed at a time. For each combination, three injections were carried out, using a working solution containing $70 \mu \mathrm{g} \mathrm{mL}-1$ of dihydralazine and hydrochlorothiazide. Finally, robustness of the method was expressed in the forms of asymmetry factors and peak areas.

\section{Linearity}

Stock solutions of dihydralazine and hydrochlorothiazide $\left(1 \mathrm{mg} \mathrm{mL}{ }^{-1}\right.$ ) were used to obtain the working solutions of the drugs in the range from 20 to $120 \mu \mathrm{gL}^{-1}$. Then, six injections were made onto the column for each concentration. The peak areas were plotted against the corresponding concentration of the drugs to construct the calibration equations. The limit of detection (LOD) and the limit of quantification (LOQ) were determined from the standard deviation of the intercepts and slopes of the calibration lines at low concentrations, using 3.3 and 10 factors for LOD and LOQ, respectively.

\section{Precision and Accuracy}

Precision was determined by analyzing the working solutions containing 30,70 and $110 \mu \mathrm{gL}^{-1}$ of dihydralazine and hydrochlorothiazide, three times during the same day and then on three subsequent days. Accuracy was estimated by determining both active substances in six model mixtures and comparing the determined amounts to the nominal values. The weighed portions of powdered tablets containing $25 \mathrm{mg}$ of dihydralazine and $25 \mathrm{mg}$ hydrochlorothiazide were transferred to $25 \mathrm{ml}$ volumetric flasks with ca. $15 \mathrm{~mL}$ of methanol, sonicated for $30 \mathrm{~min}$, diluted to the mark and
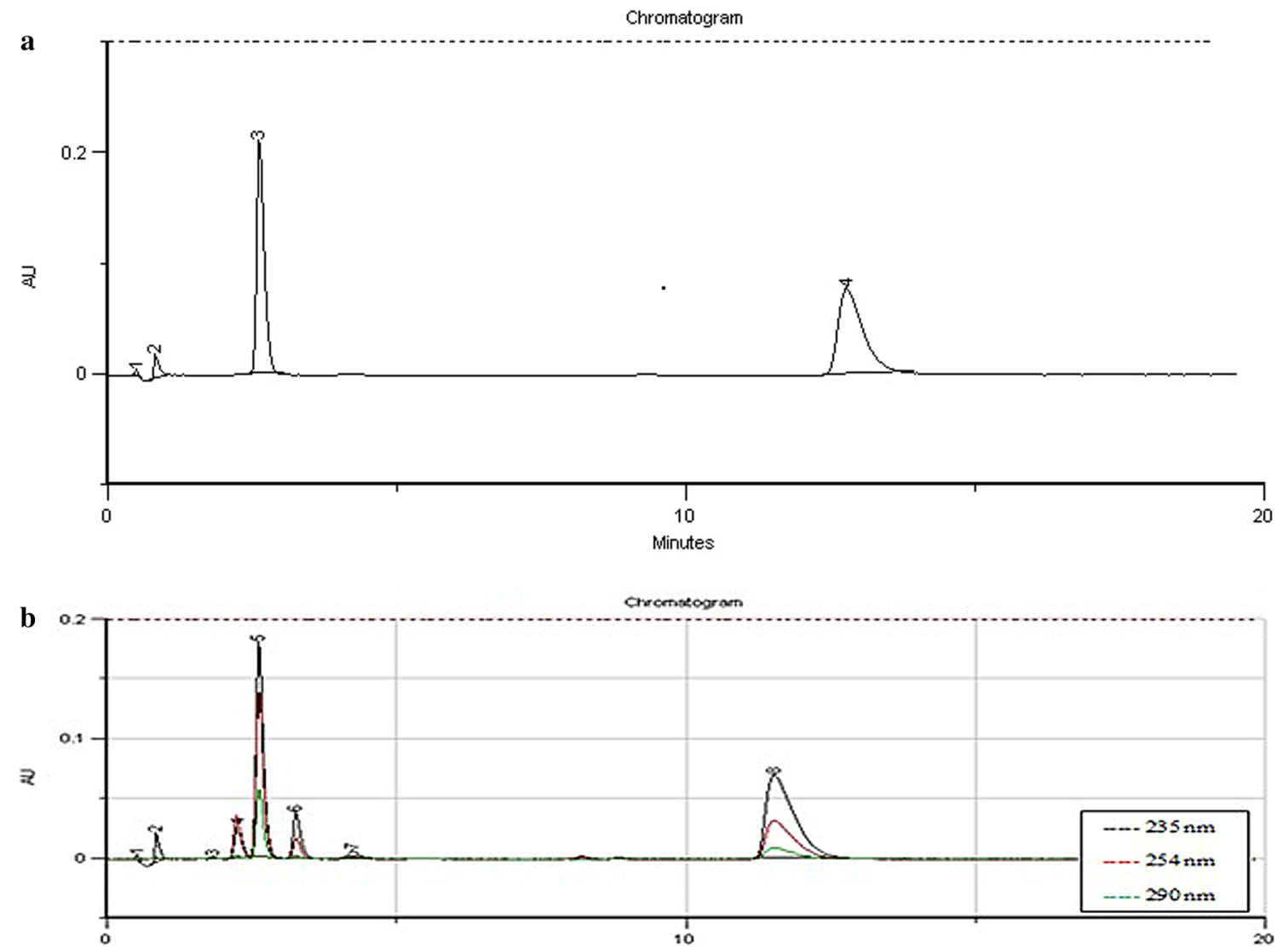

Fig. 1 Chromatograms HPLC-UV: a dihydralazine (4) and hydrochlorothiazide (3) in the calibration solutions; b dihydralazine (8) and hydrochlorothiazide (5) in the presence of their degradation products $(3,4,6,7)$ 
filtered by nylon membrane filters $(0.45 \mu \mathrm{m})$. Then, $0.6 \mathrm{~mL}$ volumes were diluted to $10 \mathrm{~mL}$ and analyzed by the HPLC method described above. The assay was repeated six times, individually weighing the respective tablet powders.

The concentrations of dihydralazine or hydrochlorothiazide were calculated using respective calibration equations and expressed as RSD for precision and percentage recovery for accuracy.

\section{Degradation in a Solid State}

Solid mixture containing dihydralazine and hydrochlorothiazide was prepared by weighing equal amounts of individual substances and mixing them thoroughly in an agate mortar. Individual substances and their mixture were placed in standardized small flat vessels, so that the thickness of the layer was approximately $3 \mathrm{~mm}$. The samples were placed

Table 1 Validation of HPLC-UV method for simultaneous determination of dihydralazine and hydrochlorothiazide

\begin{tabular}{lll}
\hline Parameter & Dihydralazine & Hydrochlorothiazide \\
\hline Linearity range $\left(\mu \mathrm{g} \mathrm{mL}^{-1}\right)$ & $20-120$ & $20-120$ \\
Slope & 344,398 & 271,311 \\
SD of slope & 3134 & 1361 \\
Intercept & $-2,333,333$ & $-127,834$ \\
SD for intercept & 471,404 & 74,342 \\
$R^{2}$ & 0.99886 & 0.99895 \\
SD of $R^{2}$ & 0.00053 & 0.00032 \\
LOD ( $\mu$ g mL $\left.{ }^{-1}\right)$ & 4.52 & 0.90 \\
LOQ ( $\mu$ g mL $\left.{ }^{-1}\right)$ & 13.69 & 2.74 \\
Accuracy $(\%$ recovery) & $99.24-101.03$ & $99.45-101.54$ \\
Precision $(\mathrm{RSD})$ & & \\
Intra-day & $0.59-1.16$ & $0.47-1.72$ \\
Inter-day & $0.90-1.07$ & $0.81-1.57$ \\
Retention time (min) & 13.21 & 2.73 \\
Asymmetry factor & 1.5 & 1.0 \\
\hline
\end{tabular}

Table 2 Percentage level of degradation of dihydralazine and hydrochlorothiazide under high temperature/humidity and under UV/Vis light

\begin{tabular}{|c|c|c|c|c|}
\hline \multirow[t]{3}{*}{ Stress conditions } & \multicolumn{4}{|c|}{ Level of degradation (\%) } \\
\hline & \multicolumn{2}{|c|}{ Dihydralazine } & \multicolumn{2}{|c|}{ Hydrochlorothiazide } \\
\hline & Individual & Mixture & Individual & Mixture \\
\hline $70{ }^{\circ} \mathrm{C} / 80 \% \mathrm{RH}$ & 22.00 & 29.70 & 12.83 & 17.72 \\
\hline $1 \mathrm{ICH}$ & 2.85 & 28.98 & 16.71 & 19.93 \\
\hline $3 \mathrm{ICH}$ & 13.26 & 59.58 & 27.78 & 33.99 \\
\hline $6 \mathrm{ICH}$ & 100.0 & 100.0 & 66.92 & 89.42 \\
\hline
\end{tabular}

in a climate chamber KBF P240 from Binder (Neckarsulm, Germany) at $70{ }^{\circ} \mathrm{C}$ and $80 \%$ RH for 2 months. After forced degradation, $10 \mathrm{mg}$ of individual substances or $20 \mathrm{mg}$ of the mixture were weighed and dissolved with methanol to obtain solutions of concentration $1.0 \mathrm{mg} \mathrm{mL}^{-1}$. After diluting with methanol to cover the linearity range, the solutions were analyzed by our HPLC-UV method. The procedure was repeated three times for each sample, and the concentrations of dihydralazine or hydrochlorothiazide remaining after degradation were calculated from the linear calibration equations.
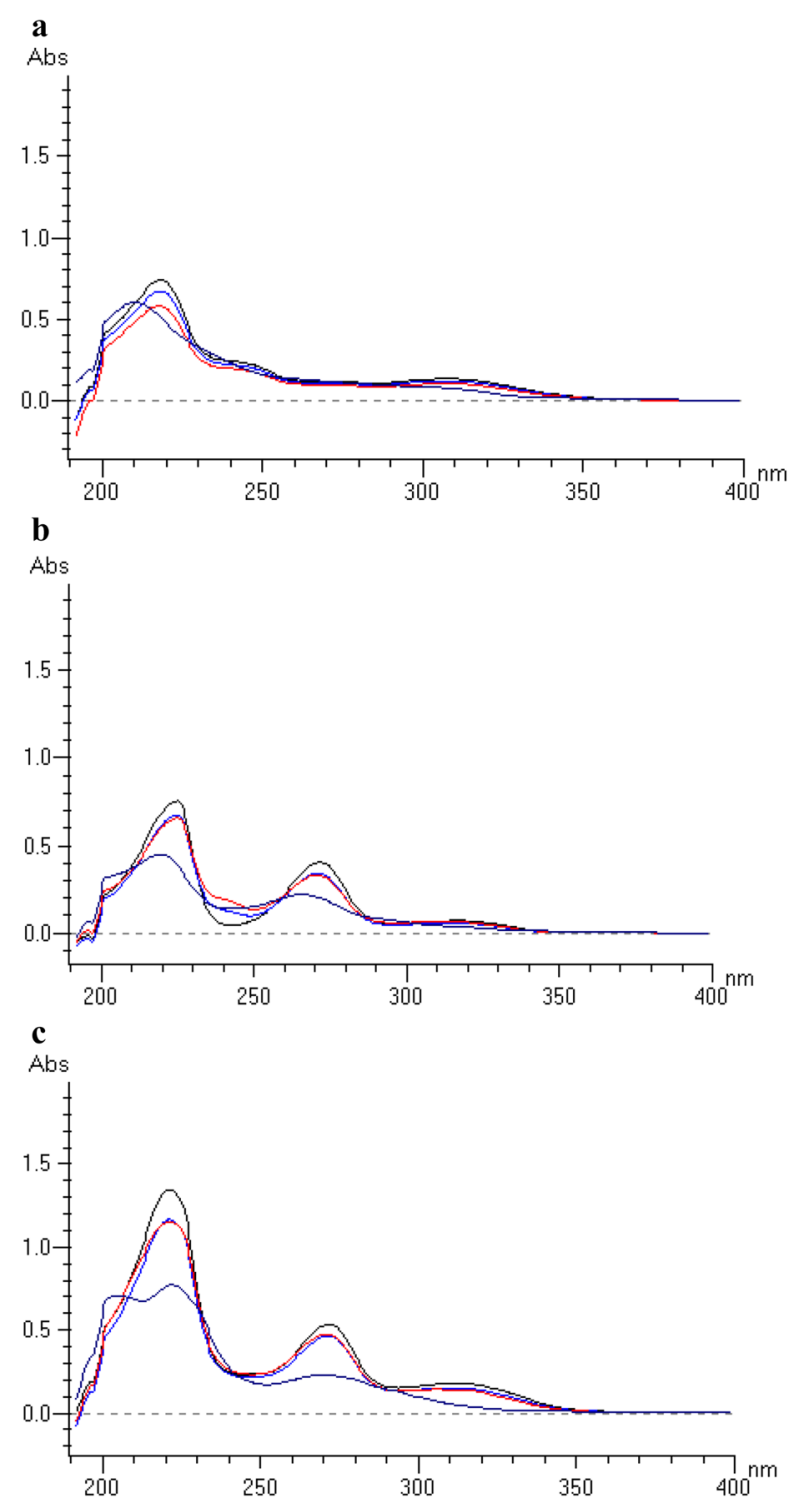

Fig. 2 a UV/Vis spectra of dihydralazine, b hydrochlorothiazide and $\mathbf{c}$ their mixture after photodegradation study: black line-standard (non-stressed sample), blue line-sample under 1 ICH dose, red line-sample under $3 \mathrm{ICH}$ doses and violet line-sample after $6 \mathrm{ICH}$ doses 


\section{Degradation in a Liquid State}

\section{Photodegradation}

Equal volumes $(2 \mathrm{~mL})$ of the stock solutions of dihydralazine or hydrochlorothiazide $\left(4 \mathrm{mg} \mathrm{mL}^{-1}\right)$ were dispensed to quartz glass-stoppered dishes (individually stressed drugs). Equal volumes $(1 \mathrm{~mL})$ of the stock solutions of dihydralazine or hydrochlorothiazide $\left(8 \mathrm{mg} \mathrm{mL}^{-1}\right)$ were mixed in quartz glass-stoppered dishes to obtain the mixtures. The samples were placed in a Suntest CPS Plus chamber from Atlas (Linsengericht, Germany) and exposed to UV/Vis light in the range $300-800 \mathrm{~nm}$, with energy equal to $18,902,56,706$ and $113,412 \mathrm{~kJ} \mathrm{~m}^{2-1}$. After forced degradation, the solutions were diluted with methanol to cover the linearity range and analyzed by our HPLC-UV method. The procedure was repeated three times for each sample, and the concentrations of non-degraded dihydralazine or hydrochlorothiazide were calculated from the linear calibration equations.

\section{Kinetics}

From the stock solutions of dihydralazine or hydrochlorothiazide $\left(4 \mathrm{mg} \mathrm{mL}^{-1}\right), 1 \mathrm{~mL}$ volumes were dispensed to small glass tubes from Medlab (Raszyn, Poland) (individually stressed drugs). From the stock solutions of dihydralazine or hydrochlorothiazide $\left(8 \mathrm{mg} \mathrm{mL}^{-1}\right), 0.5 \mathrm{~mL}$ volumes were dispensed in a similar way and mixed together. To each tube, $1 \mathrm{~mL}$ of appropriate stressor $(1 \mathrm{M} \mathrm{HCl}, 1 \mathrm{M} \mathrm{NaOH}$, buffers of $\mathrm{pH}$ 4, 7 and 10) was added. The tubes were tightly closed with stoppers and placed in a thermostated water bath from WSL (Warszawa, Poland) at $80^{\circ} \mathrm{C}$. The samples were removed from the bath after subsequently $15,30,45,60,75,90,105,120,135$, 150, 165, 180, 195, 210, 225, 240, 255, 270, 285 and $300 \mathrm{~min}$. They were immediately cooled and neutralized if necessary.
After diluting with methanol to covering the linearity range, each sample was analyzed using our HPLC-UV method. The procedure was repeated three times for each sample, and the concentrations of non-degraded dihydralazine or hydrochlorothiazide were calculated from the linear calibration equations.

When the level of degradation was at least $30 \%$ during $300 \mathrm{~min}$, kinetic parameters were calculated. The logarithm of the concentration of non-degraded substance was plotted against time of degradation to determine the order of reactions. The equations $y=a x+b$ and $R^{2}$ coefficients were obtained from which further kinetic parameters, i.e., degradation rate constant $(k)$ and degradation time of $50 \%$ substance $\left(t_{0.5}\right)$ were calculated.

\section{LC-DAD and LC-MS Methods}

Before analysis, the buffers were removed from the samples using Bakerbond SPE C8 disposable extraction columns ( $3 \mathrm{~mL}$ ) from J.T. Baker and an UCT positive pressure Manifold station (Horsham, PA, USA). The ions were removed from the bed with water, and then substances of interest were eluted with methanol. Respective fractions were pooled and dried under vacuum. Before LC analysis, they were reconstituted with acetonitrile.

The samples were analyzed with a 6530B accuratemass-QTOF-MS spectrometer with a dual ESI-Jet Stream ion source, using an Eclipse XDB C18 $(150 \times 4.6 \mathrm{~mm}$, $3.5 \mu \mathrm{m}$ ) column from Agilent Technologies (Santa Clara, CA, USA). The chromatograph was equipped with a DAD, an autosampler, a binary gradient pump, and a column oven. Acetonitrile-water $(1: 99, \mathrm{v} / \mathrm{v})$ with $10 \mathrm{mM}$ ammonium formate $(0.1 \%)$ (solvent A) and acetonitrile-water $(95: 5, \mathrm{v} / \mathrm{v})$ with $10 \mathrm{mM}$ ammonium formate $(0.1 \%)$ (solvent B) were used as mobile phases. The following elution procedure was
Table 3 Percentage level of degradation and kinetic parameters of degradation of dihydralazine in solutions

\begin{tabular}{|c|c|c|c|c|c|}
\hline Stress conditions & $\begin{array}{l}\text { Degradation after } \\
300 \text { min }(\%)\end{array}$ & Linear equation, $y=a x+b$ & $R^{2}$ & $k\left(\mathrm{~s}^{-1}\right)$ & $t_{0.5}(\mathrm{~h})$ \\
\hline \multicolumn{6}{|l|}{ Dihydralazine } \\
\hline $1 \mathrm{M} \mathrm{HCl}$ & 1.61 & $\mathrm{nc}$ & $\mathrm{nc}$ & $\mathrm{nc}$ & $\mathrm{nc}$ \\
\hline Buffer pH 4 & 5.50 & $\mathrm{nc}$ & $\mathrm{nc}$ & $\mathrm{nc}$ & $\mathrm{nc}$ \\
\hline Buffer pH 7 & 38.54 & $y=-0.0018 x+4.7378$ & 0.8820 & $2.70 \times 10^{-5}$ & 7.13 \\
\hline Buffer pH 10 & 74.98 & $y=-0.0043 x+4.7449$ & 0.9665 & $7.70 \times 10^{-5}$ & 2.50 \\
\hline $1 \mathrm{M} \mathrm{NaOH}$ & 100.0 & $y=-0.0184 x+4.0556$ & 0.9989 & $5.09 \times 10^{-4}$ & 0.38 \\
\hline \multicolumn{6}{|c|}{ Dihydralazine in the mixture with hydrochlorothiazide } \\
\hline $1 \mathrm{M} \mathrm{HCl}$ & 51.06 & $y=-0.0064 x+4.9381$ & 0.9871 & $3.97 \times 10^{-5}$ & 4.85 \\
\hline Buffer pH 4 & 82.39 & $y=-0.0064 x+4.9381$ & 0.9871 & $9.65 \times 10^{-5}$ & 1.99 \\
\hline Buffer pH 7 & 100.0 & $y=-0.0080 x+4.4918$ & 0.8243 & $3.28 \times 10^{-4}$ & 1.50 \\
\hline Buffer pH 10 & 100.0 & $y=-0.0092 x+4.7455$ & 0.9805 & $3.53 \times 10^{-4}$ & 1.26 \\
\hline $1 \mathrm{M} \mathrm{NaOH}$ & 100.0 & $y=-0.0047 x+4.6211$ & 0.9866 & $9.02 \times 10^{-5}$ & 2.13 \\
\hline
\end{tabular}

$n c$ non-calculated 
Table 4 Percentage level of degradation and kinetic parameters of degradation of hydrochlorothiazide in solutions

\begin{tabular}{|c|c|c|c|c|c|}
\hline Stress conditions & $\begin{array}{l}\text { Degradation after } \\
300 \min (\%)\end{array}$ & Linear equation, $y=a x+b$ & $R^{2}$ & $k\left(\mathrm{~s}^{-1}\right)$ & $t_{0.5}(\mathrm{~h})$ \\
\hline \multicolumn{6}{|c|}{ Hydrochlorothiazide } \\
\hline $1 \mathrm{M} \mathrm{HCl}$ & 52.29 & $y=-0.0018 x+4.5315$ & 0.8117 & $3.11 \times 10^{-5}$ & 4.68 \\
\hline Buffer pH 4 & 23.64 & $y=-0.0007 x+4.7441$ & 0.9366 & $1.50 \times 10^{-5}$ & 12.83 \\
\hline Buffer $\mathrm{pH} 7$ & 36.34 & $y=-0.0011 x+4.6498$ & 0.9642 & $2.50 \times 10^{-5}$ & 7.67 \\
\hline Buffer $\mathrm{pH} 10$ & 36.99 & $y=-0.0012 x+4.7004$ & 0.9506 & $2.51 \times 10^{-5}$ & 7.49 \\
\hline $1 \mathrm{M} \mathrm{NaOH}$ & 37.97 & $y=-0.0006 x+4.7518$ & 0.9781 & $1.29 \times 10^{-5}$ & 15.91 \\
\hline \multicolumn{6}{|c|}{ Hydrochlorothiazide in the mixture with dihydralazine } \\
\hline $1 \mathrm{M} \mathrm{HCl}$ & 53.98 & $y=-0.0019 x+4.5717$ & 0.9862 & $4.31 \times 10^{-5}$ & 4.47 \\
\hline Buffer $\mathrm{pH} 4$ & 70.71 & $y=-0.0038 x+4.5422$ & 0.9391 & $6.79 \times 10^{-5}$ & 2.82 \\
\hline Buffer pH 7 & 93.72 & $y=-0.0096 x+4.4038$ & 0.9143 & $1.54 \times 10^{-4}$ & 1.25 \\
\hline Buffer pH 10 & 94.14 & $y=-0.0081 x+4.6094$ & 0.9190 & $1.58 \times 10^{-4}$ & 1.22 \\
\hline $1 \mathrm{M} \mathrm{NaOH}$ & 47.56 & $y=-0.0017 x+4.7004$ & 0.9438 & $3.59 \times 10^{-5}$ & 5.36 \\
\hline
\end{tabular}

Fig. 4 Fragmentation pattern of dihydralazine in negative ioni-

zation mode: CID off set $10 \mathrm{~V}$

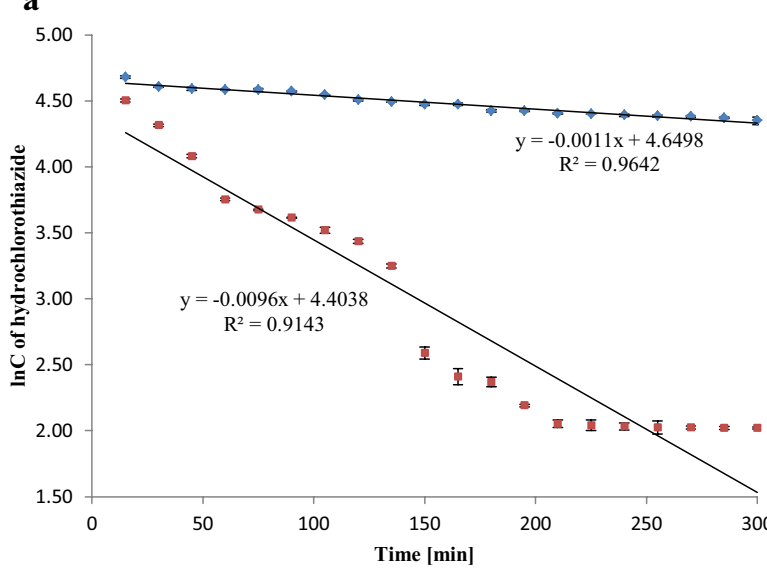<smiles>N/N=c1\[nH][nH]/c(=N\N)c2ccccc12</smiles>

Exact Mass: 189,09<smiles>CCCc1ccccc1/C(=N/N)NNCc1ccccc1</smiles>

$\mathrm{C}_{8} \mathrm{H}_{9} \mathrm{~N}_{4}^{-}$ Exact Mass: 161,08<smiles>Cc1ccccc1C=N</smiles>

$\mathrm{C}_{8} \mathrm{H}_{8} \mathrm{~N}^{-}$

Exact Mass: 118,07
Fig. 3 First-order plots of drugs degradation in the buffer of $\mathrm{pH} 7$ : a dihydralazine degraded as an individual and in the mixture with hydrochlorothiazide; b hydrochlorothiazide degraded as an individual and in the mixture with dihydralazine. Errors bars on the curves represent the SD values of triplicate samples adopted: 0-60 $\min , 0-95 \%$ of solvent $B$ with a stable flow rate $0.4 \mathrm{~mL} \mathrm{~min}^{-1}$. The injection volume for the samples was $10 \mu \mathrm{L}$. The analysis was conducted at $25^{\circ} \mathrm{C}$.

LC/MS analysis was performed according to the following parameters of the ion source: a negative ion mode (-ESI), gas $\left(\mathrm{N}_{2}\right)$ flow rate $12 \mathrm{~L} \mathrm{~min}^{-1}$, nebulizer pressure 
35 psig, vaporizer temperature $350{ }^{\circ} \mathrm{C}$, sheath gas temperature $400{ }^{\circ} \mathrm{C}$, sheath gas $\left(\mathrm{N}_{2}\right)$ flow $12 \mathrm{~L} \mathrm{~min}^{-1}, \mathrm{~m} / \mathrm{z}$ range 100-1000 mass units with an acquisition mode auto MS/MS, collision induced dissociation (CID) 10 and $40 \mathrm{eV}$ with MS scan rate of 1 spectrum per s and 2 spectra per cycle, VCap $4000 \mathrm{~V}$, skimmer $65 \mathrm{~V}$, fragmentor $150 \mathrm{~V}$ and Octopole RF Peak $750 \mathrm{~V}$. Additionally, the analysis was made in auto MS/ MS with excluded $\mathrm{m} / \mathrm{z}$ at 966.0007 and 112.9856 for negative ion mode, corresponding to the $\mathrm{m} / \mathrm{z}$ of reference ions.

The obtained experimental mass values were used to generate molecular formula of the products, on which basis their structures were predicted. The most postulated structures were justified through the mechanisms of their formation.

\section{Results and Discussion}

\section{Development and Validation of LC-UV Method}

A simple, isocratic HPLC-UV method was developed for simultaneous determination of dihydralazine and hydrochlorothiazide in presence of their degradation products. It is worth mentioning that similar reports concerning dihydralazine were not found in the literature.

At the beginning, several trials were carried out to obtain good resolution between the drugs and their degradation products. They involved the use of different columns, mobile phases and flow rates. First, C 8 and C18 columns $(125 \times 4.0 \mathrm{~mm}, 5 \mu \mathrm{m})$ were used and the mixtures containing water, methanol and acetonitrile as mobile phases. As far as $\mathrm{C} 8$ column was concerned, any mixture and any flow rate of the mobile phase $\left(0.8-1.8 \mathrm{~mL} \mathrm{~min}^{-1}\right)$ did not result in sufficient separation of hydrochlorothiazide and its degradation products. All peaks of interest showed retention times below $2 \mathrm{~min}$. When a C18 column was used, it was showed that content of acetonitrile in the mobile phase could not exceed $20 \%$ to obtain symmetrical peaks of hydrochlorothiazide. However, its retention time was still very short and resolution between the peaks of degradation products was not achieved. Thus, addition of ion pair reagents was decided and one of them, i.e., tetrabutylammonium hydrogen sulfate was effective in good separation of the peaks of interest.

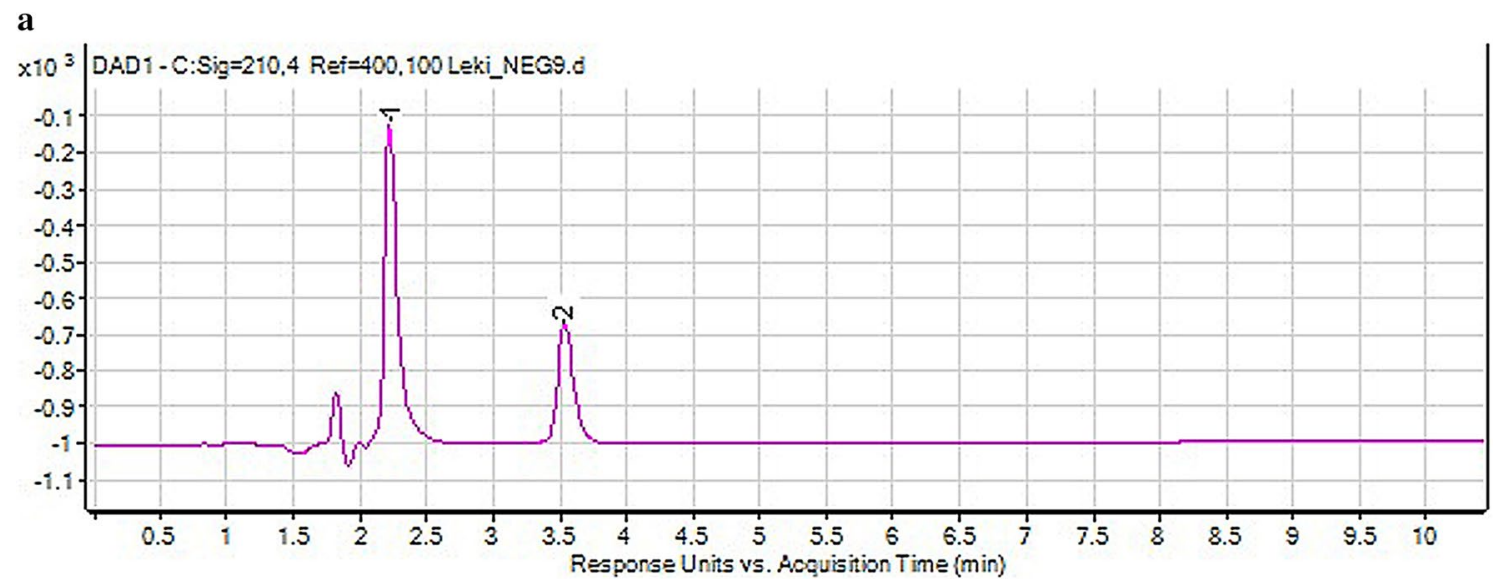

b

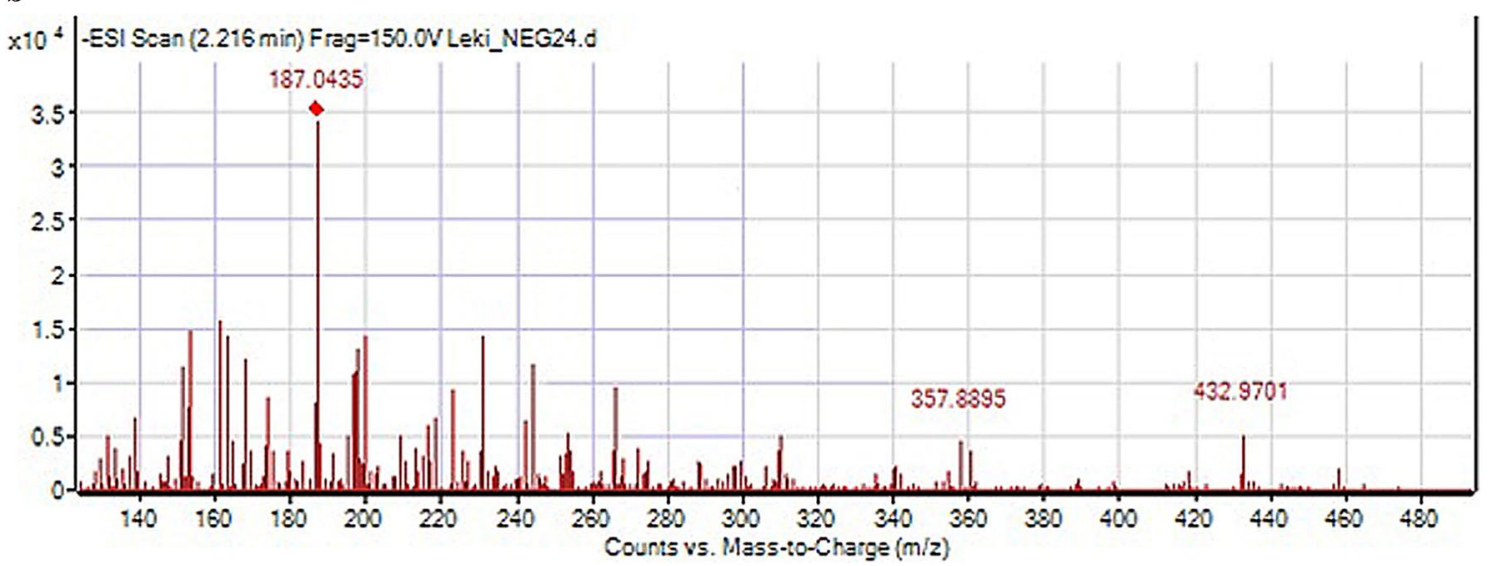

Fig. 5 a Chromatogram DAD of dihydralazine (1) and its degradation product (2) in $1 \mathrm{M} \mathrm{NaOH}$. b Negative ion ESI LC/MS of degradation product of dihydralazine (1,4-dihydrazinylidenophthalazine); CID off set $10 \mathrm{~V}$ 
However, retention of dihydralazine was too strong in these conditions (retention times above $20 \mathrm{~min}$ ). Therefore, a CN column was tried together with mobile phases containing not more than $20 \%$ of acetonitrile. It was showed that the retention time of hydrochlorothiazide was still very short while that of dihydralazine was very long. Thus, acetonitrile content was decreased to $15 \%$ and ion pair reagent (tetrabutylammonium hydrogen sulphate) was added. As a result, the retention time of hydrochlorothiazide was extended to ca. $3 \mathrm{~min}$, while that of dihydralazine shortened to ca. $13 \mathrm{~min}$, maintaining an acceptable shape of the peaks. A huge difference in retention times of dihydralazine and hydrochlorothiazide was still observed but separation of all peaks of interest was possible. Respective chromatograms showed that the peaks of dihydralazine and hydrochlorothiazide were free from interferences of the degradation products, confirming selectivity of the method (Fig. 1).

Resistance to small changes in analytical parameters, i.e., acetonitrile content $(15 \pm 2 \%)$, $\mathrm{pH}(3.5 \pm 0.1$ unit $)$, flow rate $\left(1.4 \pm 0.2 \mathrm{ml} \mathrm{mL}^{-1}\right)$, detection wavelength $(235 \pm 3 \mathrm{~nm})$ and column temperature $\left(25 \pm 2{ }^{\circ} \mathrm{C}\right)$ was examined. Uniformity of the obtained peak areas confirmed the robustness of the method. However, the calculated values of peak symmetry indicated sensitivity of the method to changes of detection wavelength and flow rate of the mobile phase.
The method was found to be linear over the concentration range of $20-120 \mu \mathrm{g} \mathrm{mL} \mathrm{m}^{-1}$ for both drugs, with average $R^{2}$ of 0.9989 for dihydralazine and 0.9990 for hydrochlorothiazide. The calculated LOD and LOQ were 4.52 and $13.69 \mu \mathrm{g} \mathrm{mL}^{-1}$ for dihydralazine, and 0.90 and $2.74 \mu \mathrm{g} \mathrm{mL}^{-1}$ for hydrochlorothiazide. The RSD values in the range $0.59-1.16 \%$ for dihydralazine and $0.47-1.72 \%$ for hydrochlorothiazide (1-day precision), and $0.90-1.07 \%$ for dihydralazine and $0.81-1.57 \%$ for hydrochlorothiazide (inter-day precision) were obtained. Accuracy of the method was confirmed by determining both drugs in powdered tablets. Recovery values were obtained in the range 99.24-100.99\% for dihydralazine and $99.45-101.54 \%$ for hydrochlorothiazide (Table 1). The chromatograms obtained for the samples of powdered tablets showed the peaks of interest free from interferences of excipients, confirming selectivity of the method.

\section{Degradation in a Solid State}

Our study showed that dihydralazine was sensitive to high temperature and humidity $(22.01 \%$ degradation after 2 months at $70{ }^{\circ} \mathrm{C} / 80 \% \mathrm{RH}$ ). In the mixture with hydrochlorothiazide, there was further increase of degradation to $29.70 \%$ (Table 2). Therefore, it could be concluded that degradation of dihydralazine was accelerated by hydrochlorothiazide.

Table 5 The identified degradation products of dihydralazine and hydrochlorothiazide

(n)


In the literature, a similar effect of hydrochlorothiazide was documented for its solid mixture with cilazapril [38].

After 2 months at $70{ }^{\circ} \mathrm{C} / 80 \% \mathrm{RH}$, hydrochlorothiazide as individual showed degradation equal to $12.83 \%$. According to the literature, the highest degradation of hydrochlorothiazide (ca. $15 \%$ ) occurred at $100{ }^{\circ} \mathrm{C}$ (after $5 \mathrm{~h}$ ) [25] and $65{ }^{\circ} \mathrm{C}$ (after $24 \mathrm{~h}$ ) [26]. In the mixture with dihydralazine, an increase of hydrochlorothiazide degradation to $17.72 \%$ was observed (Table 2).

These data allowed to draw the conclusion on mutual influence of both dihydralazine and hydrochlorothiazide on their stability. As a consequence, the need to adequately protect these active substances from high temperature and humidity was clearly shown.

\section{Photodegradation}

In our study, the energy of $18,902 \mathrm{~kJ} \mathrm{~m}^{2-1}$ or $1 \mathrm{ICH}$ dose was equivalent to $1,200,000 \mathrm{~lx} \mathrm{~h}$ and $200 \mathrm{~W} \mathrm{~m}^{2-1}$ [39]. Dihydralazine fulfilled the requirements of the test confirming photostability, because its percentage degradation was
$2.85 \%$. However, under higher exposures, its degradation was $13.26 \%\left(56,706 \mathrm{~kJ} \mathrm{~m}^{2-1}\right.$ or $3 \mathrm{ICH}$ doses $)$ and $100 \%$ $\left(113,412 \mathrm{~kJ} \mathrm{~m}^{2-1}\right.$ or $6 \mathrm{ICH}$ doses). In addition, its UV/Vis spectrum changed after these expositions (Fig. 2a). Dihydralazine mixed with hydrochlorothiazide underwent higher photodegradation than an individual substance. Under energy equal $1 \mathrm{ICH}$ dose, the level of degradation rose to $28.98 \%$ (Table 2). These data allowed to draw the conclusion that hydrochlorothiazide increased sensitivity of dihydralazine to light. It was also observed as changes in respective UV/Vis spectra (Fig. 2c). To the best of our knowledge, the results presented here are the first in the area of photostability of dihydralazine.

Present experiment showed that hydrochlorothiazide was sensitive to light (16.71\% degradation upon energy equivalent to $1 \mathrm{ICH}$ dose) (Table 2). According to the literature, similar level of degradation (ca. 18\%) was observed under monochromatic light at $256 \mathrm{~nm}$ [25]. However, much lower photodegradation $(0.1-5.5 \%)$ was also reported $[29,30]$. In our experiment, the influence of light was confirmed by changes in the UV/Vis spectra of the stressed samples. After

\section{a}

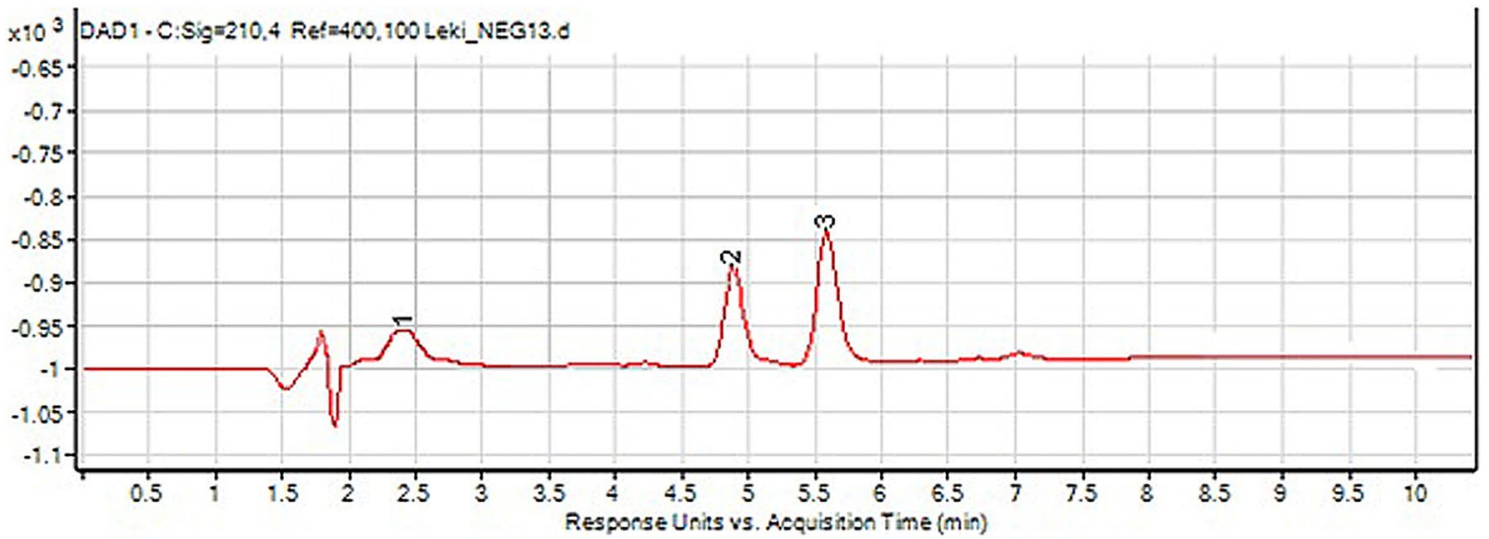

b

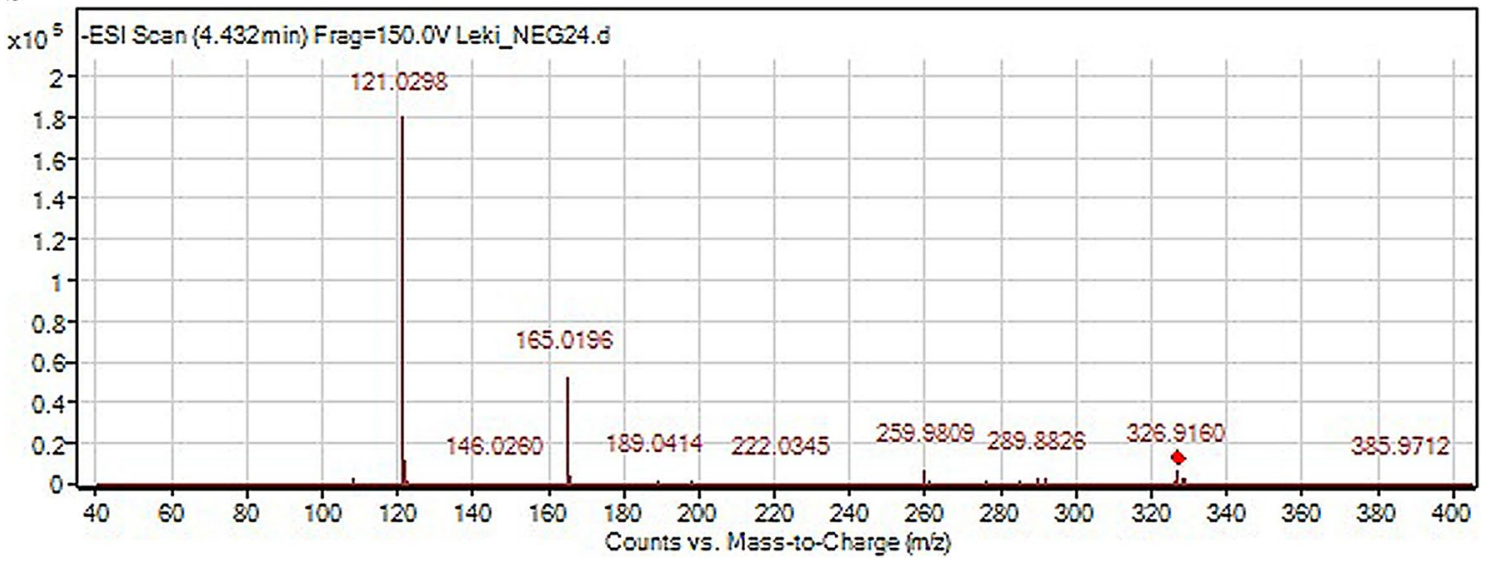

Fig. 6 a Chromatogram DAD of dihydralazine (1) and its degradation products $(2,3)$ under UV/Vis light. b Negative ion ESI LC/MS of degradation product of dihydralazine (2): CID of set $10 \mathrm{~V}$ 
Fig. 7 Proposed degradation pathway of dihydralazine in $1 \mathrm{M}$ $\mathrm{NaOH}$ and under UV/Vis light<smiles>NN=C1N=NC(=NN)c2ccccc21</smiles><smiles>N#CCN1CNc2cc(Cl)c(S(N)(=O)=O)cc2S1(=O)=O</smiles>

$\mathrm{C}_{7} \mathrm{H}_{7} \mathrm{ClN}_{3} \mathrm{O}_{4} \mathrm{~S}_{2}^{-}$

Exact Mass: 295,96<smiles>Nc1cc(Cl)c(S(N)(=O)=O)cc1S(=O)(=O)OCCCCO</smiles>

Exact Mass: 268,95<smiles>CC(C)NS(=O)(=O)c1ccc(N)cc1Cl</smiles>

$\mathrm{C}_{6} \mathrm{H}_{6} \mathrm{ClN}_{2} \mathrm{O}_{2} \mathrm{~S}^{-}$

Exact Mass: 204,98

Fig. 8 Fragmentation pattern of hydrochlorothiazide in negative ionization mode: CID off set $10 \mathrm{~V}$

$6 \mathrm{ICH}$ doses, a clear shifting of one of the absorption maximum of hydrochlorothiazide was observed (Fig. 1b). It confirmed photosensitivity of hydrochlorothiazide and indicated the need to apply appropriate photoprotection for pure drug and its formulations.

Hydrochlorothiazide mixed with dihydralazine was more degraded in comparison with an individual substance (19.93 vs. $16.71 \%, 33.99$ vs. $27.78 \%$ and 89.42 vs. $66.92 \%$ after 1,3 and 6 ICH doses, respectively) (Table 2). The above data as well as respective UV/Vis spectra confirmed the mutual influence of both components on their photostability (Fig. 2c).

\section{Degradation in a Liquid State}

The present study proved stability of dihydralazine in a strongly acidic environment $(1.61 \%$ of degradation in $1 \mathrm{M}$ $\mathrm{HCl}$ after $300 \mathrm{~min}$ ). On the contrary, the highest decomposition was observed in a strongly alkaline environment ( $100 \%$ of degradation in $1 \mathrm{M} \mathrm{NaOH}$ ). In addition, the substance degraded in buffers of $\mathrm{pH} 4,7$ and $10(5.50,38.54$ and $74.98 \%$ of degradation, respectively). Dihydralazine in a mixture was degraded to a much greater extent. The greatest increase of degradation occurred in the buffer of $\mathrm{pH} 7$ (100 vs. $38.54 \%$ ). In addition, a high level of degradation 


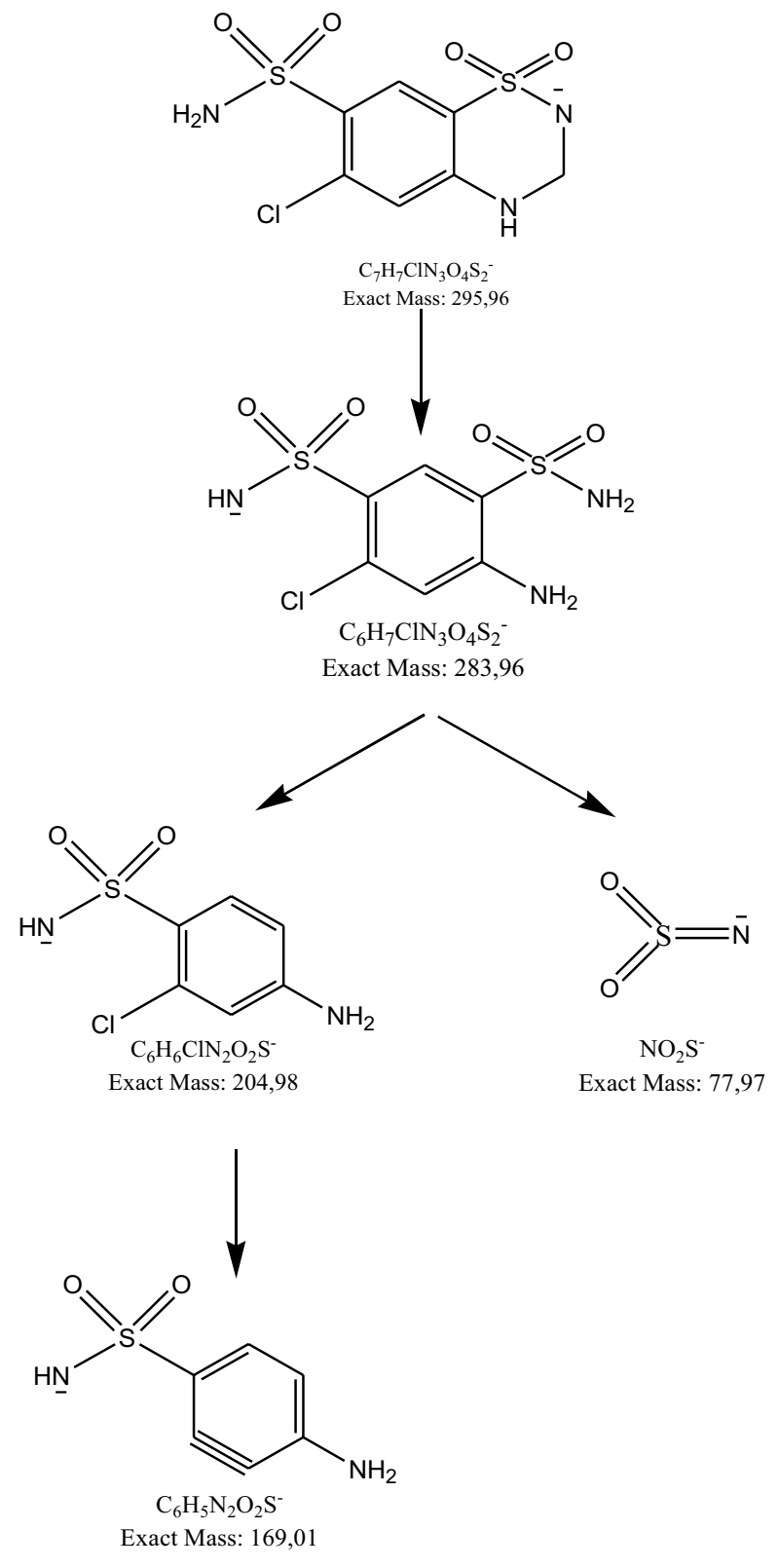

Fig. 9 Proposed degradation pathway of hydrochlorothiazide in solutions

(51.06\%) was observed in $1 \mathrm{M} \mathrm{HCl}$, where individually stressed dihydralazine showed stability (Table 3).

According to the cited works, the highest degradation of hydrochlorothiazide occurred in methanol (53.56\%) [25], $1 \mathrm{M} \mathrm{NaOH}(69.60 \%)$ and $1 \mathrm{M} \mathrm{HCl}(81.70 \%)$ [21]. In other works, degradation in acidic medium ranged from 0.4 to $17.86 \%$ while in alkaline medium from 0.15 to $36.82 \%$ [19,
20, 22, 25, 28, 30-32]. Hydrochlorothiazide was shown to be stable in the buffer of $\mathrm{pH} 2.0$ and less stable at $\mathrm{pH}$ 9.0, where $9.07 \%$ of the drug degraded [23]. Our experiments confirmed that hydrochlorothiazide was prone to degradation in $1 \mathrm{M} \mathrm{HCl}(52.29 \%)$ and $1 \mathrm{M} \mathrm{NaOH}(37.97 \%)$. Degradation in buffers of $\mathrm{pH} \mathrm{4,7}$ and 10 was higher in comparison to Ref. 23 (23.64-36.99\%), probably because of using higher temperature. Degradation of hydrochlorothiazide was further intensified in the mixture with dihydralazine. The greatest increase of degradation occurred in the buffer of $\mathrm{pH} 7$ (93.72 vs. 36.34\%) (Table 4).

\section{Kinetics}

We completed our experiments by calculating the degradation kinetics of dihydralazine and hydrochlorothiazide. It was found that degradation of dihydralazine, individually stressed and in the mixture, proceeded as the first-order reactions. Values of the rate constants $(k)$ were at the levels of $10^{-5}-10^{-4} \mathrm{~s}^{-1}$. The shortest $t_{0.5}(0.38 \mathrm{~h})$ was calculated for $1 \mathrm{M} \mathrm{NaOH}$ (Table 3). Hydrochlorothiazide degradation was also observed as the first-order reactions. Values of the observed $k$ for individually stressed hydrochlorothiazide were at the level of $10^{-5} \mathrm{~s}^{-1}$. The shortest $t_{0.5}$ was obtained in $1 \mathrm{M} \mathrm{HCl}(4.68 \mathrm{~h})$. In the mixture, the quickest degradation of hydrochlorothiazide was calculated at $\mathrm{pH}$ 7 and $10\left(k\right.$ values at the level $10^{-4} \mathrm{~s}^{-1}$ ), where the lowest values of $t_{0.5}$ were obtained $(1.22-1.25 \mathrm{~h}$ ) (Table 4$)$. In the mixture, both the substances were observed to degrade harder and faster in almost all experimental conditions. However, the biggest differences occurred in the buffer of $\mathrm{pH}$ 7. Therefore, respective data were depicted as $x y$ diagrams (Fig. 3). Due to the lack of other data in this area, the results presented here are a valuable supplement to the literature resources.

\section{Identification of Degradation Products}

As a result of negative ionization of dihydralazine, a deprotonated molecule $[\mathrm{M}-\mathrm{H}]^{-}$of $\mathrm{m} / \mathrm{z} 189.09$ was formed. Then, fragment ions of $\mathrm{m} / \mathrm{z} 161.08$ and 118.07 were produced. Based on these results, it was shown that dihydralazine was fragmented by loss of hydrazine and breaking the phenazine ring (Fig. 4). The Eur. Ph. monograph of dihydralazine lists three impurities, A (4-hydrazinophthalazin-1-amine), B (hydrazine) and C (1-hydrazinophthalazine) [2]. In our LC-DAD and LC/MS studies, a product of $\mathrm{m} / \mathrm{z} 187.04$ 
a

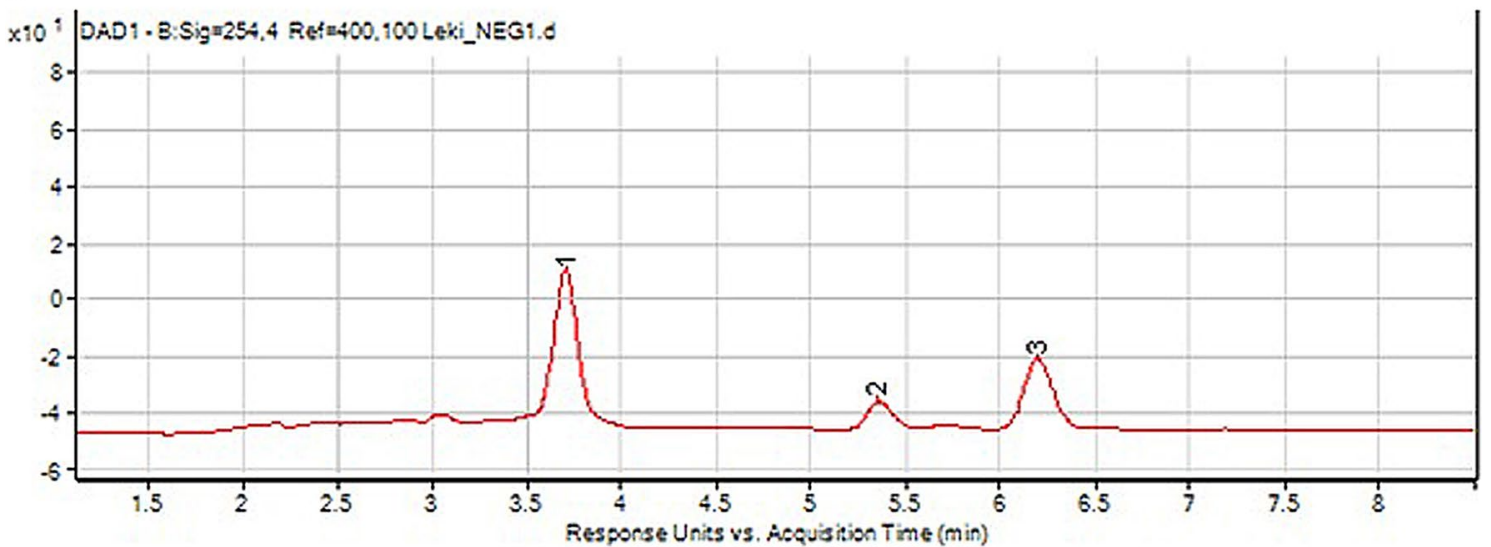

b

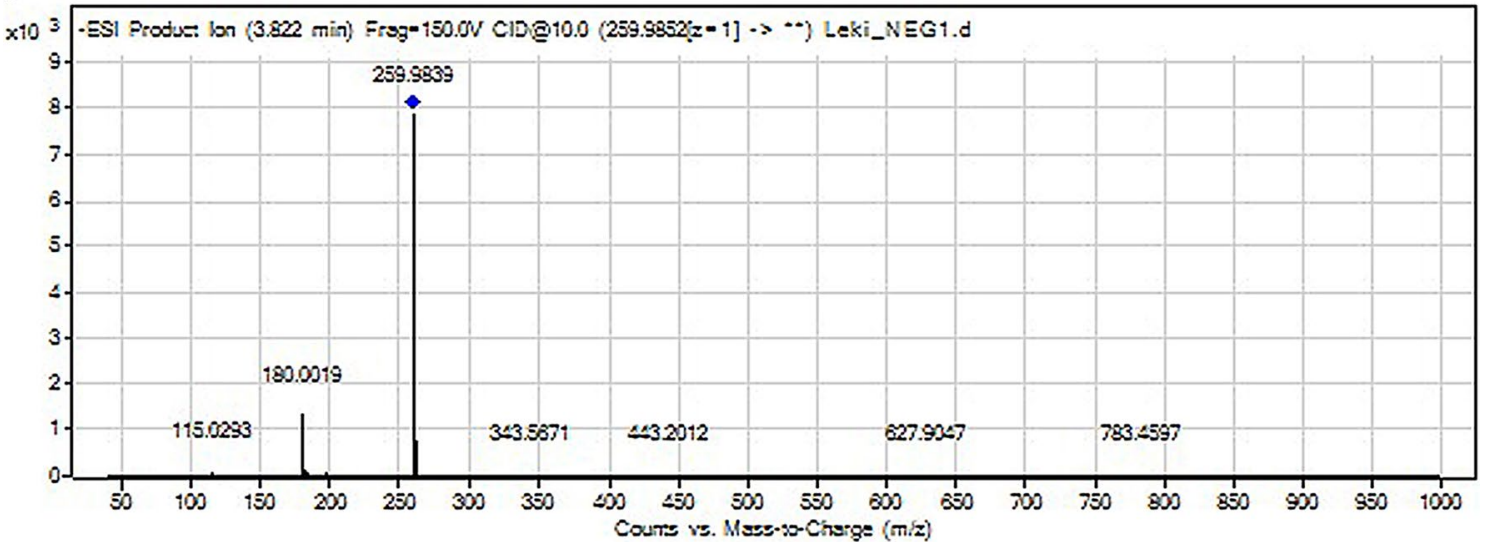

Fig. 10 a Chromatogram DAD of hydrochlorothiazide (3) and its degradation products $(1,2)$ under UV/Vis light. b Negative ion ESI LC/MS of degradation product of hydrochlorothiazide (1): CID off set 10V

was observed after degradation in $1 \mathrm{M} \mathrm{NaOH}$. The respective chromatogram and mass spectrum were presented in Fig. 5. It was identified as 1,4-dihydrazinylidenophthalazine (Table 5). Such a product was not described in the literature so far. In the buffer of $\mathrm{pH} 10$ and under UV/Vis light, two degradation products were observed as fragment ions of $m / z 121.03$ and 161.04 (Fig. 6). The first product was not described in the literature so far, while the second one was identified as impurity $\mathrm{C}$ (Table 5 ). The proposed degradation pathways for dihydralazine are presented in Fig. 7.

Using a negative ionization mode, a deprotonated molecule $[\mathrm{M}-\mathrm{H}]^{-}$of hydrochlorothiazide of $\mathrm{m} / \mathrm{z} 295.06$ was obtained from which, after losing the HCN molecule, an ion of $\mathrm{m} / \mathrm{z} 268.95$ was formed. Further fragmentation led to formation of an ion of $\mathrm{m} / z 204.98$ (loss of $\mathrm{SO}_{2}$ ) (Fig. 8). These results are consistent with previous results concerning fragmentation of hydrochlorothiazide [27]. The Eur.
Ph. monograph of hydrochlorothiazide lists three impurities, A (6-chloro-2H-1,2,4-benzothiadiazine-7-sulfonamide 1,1-dioxide, chlorothiazide), B (4-amino-6-chlorobenzene-1,3-disulfonamide) and $\mathrm{C}$ (6-chloro- $N$-[(6-chloro7-sulfamoyl-2,3-dihydro-4H-1,2,4-benzothiadiazin-4-yl 1,1-dioxide)methyl]-3,4-dihydro-2H-1,2,4-benzothiadiazine-7-sulfonamide 1,1-dioxide) [2]. In the present study, a degradation product of hydrochlorothiazide was detected as a fragment ion of $m / z$ 283.96. It was identified as impurity B. It confirmed the results obtained by Belal et al. [22] and Mahajan et al. [27] where the same product was detected as a result of acid and alkaline hydrolysis of hydrochlorothiazide. The structure of the resulting product indicated breaking of the 1,2,4-benzothiadiazine ring and loss of formaldehyde. The resulting product further fragmented yielding an ion of $\mathrm{m} / \mathrm{z} 204.98$ (loss of the sulfonamide group), from which 


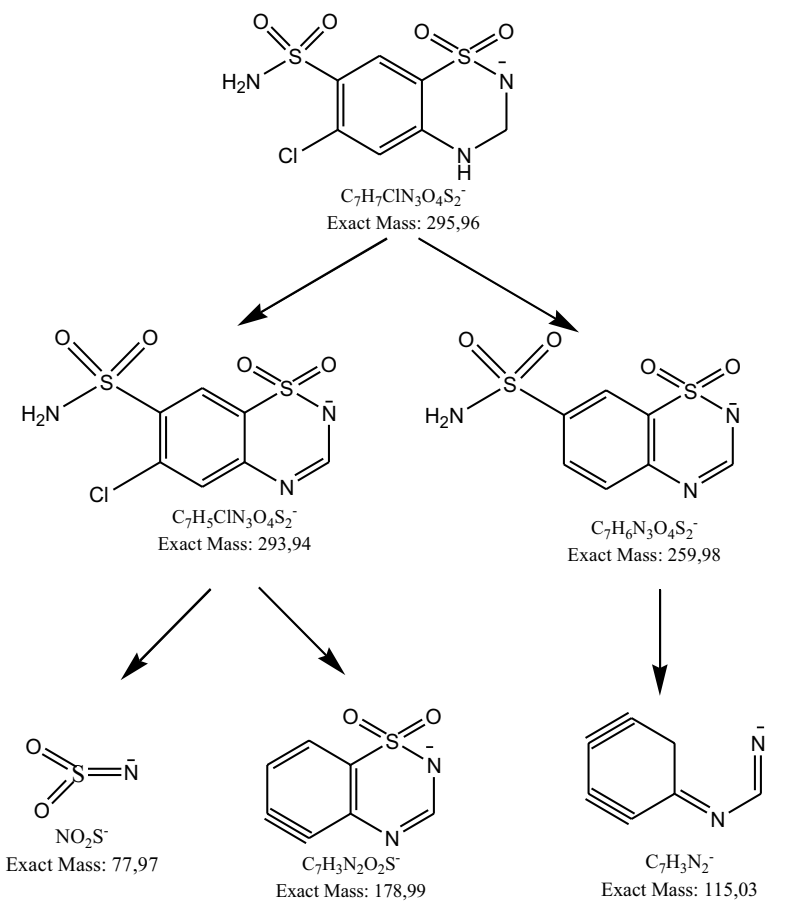

Fig. 11 Proposed degradation pathway of hydrochlorothiazide under $\mathrm{UV} / \mathrm{Vis}$ light

hydrogen chloride was detached to form an ion of $\mathrm{m} / \mathrm{z} 169.9$. The proposed fragmentation profile was drawn in Fig. 9.

Under UV/Vis light, two other fragment ions of $\mathrm{m} / \mathrm{z}$ values 293.94 and 259.98 were detected (Fig. 10). The first was identified as chlorothiazide (impurity A) [2]. The second product was not described in the literature so far and was identified as 1,2,4-benzothiadiazine-7-sulfonamide 1,1-dioxide (Table 5). Based on these results, it was concluded that light facilitated detaching the chlorine atom from the aromatic ring (Fig. 11). A similar result was observed and described for amiloride [40]. In the present experiment, chlorothiazide further fragmented by losing the sulfonamide group and hydrogen chloride yielding an ion of $\mathrm{m} / \mathrm{z}$ 178.99. Previously, only chlorothiazide was described as a result of photodegradation of the parent drug [27].

Most of these degradation products were observed in the mixture of dihydralazine and hydrochlorothiazide (fragment ions of $\mathrm{m} / \mathrm{z} 121.03,169.09,178.99,187.04$, 204.98 and 293.94). In addition, further products occurred after degradation in $1 \mathrm{M} \mathrm{HCl}(\mathrm{m} / z$ 199.07), $1 \mathrm{M}$ $\mathrm{NaOH}$, buffers $(\mathrm{m} / \mathrm{z}, 211.07)$ and under UV/Vis light $(\mathrm{m} / \mathrm{z}$ 169.05). Unfortunately, they were not identified by us. However, quite a new product of photodegradation of hydrochlorothiazide of $\mathrm{m} / \mathrm{z}, 275.98$ was detected in the mixture (Fig. 12) and identified as $2 H$-1,2,4-benzothiadiazinesulfonamide 1,1,4-trioxide (Table 5). This indicated a new way of hydrochlorothiazide photodegradation by detaching the chlorine atom and oxidation at the nitrogen atom (Fig. 13).

\section{Conclusions}

Dihydralazine in a solid state was sensitive to high temperature and humidity, while in solutions it was degraded by UV/Vis light and $\mathrm{pH}$ below 4 . Hydrochlorothiazide in a solid state was sensitive to high temperature and humidity as well as to UV/Vis light. In solutions, it degraded in $1 \mathrm{M}$ $\mathrm{HCl}, 1 \mathrm{M} \mathrm{NaOH}$, buffers and under UV/Vis light. In the stressed individual samples of dihydralazine and hydrochlorothiazide, (phenylmethyl)hydrazine and 1,2,4-benzothiadiazine-7-sulfonamide 1,1-dioxide were observed for the first time.

Percentage degradation of drugs in the mixture was greater than of individual drugs under the same stress conditions. An interesting effect was observed for dihydralazine which became sensitive to acidic degradation. Increased sensitivity of both active substances to stress and potent interactions between them were confirmed by new degradation products detected, e.g., 2H-1,2,4-benzothiadiazine-7-sulfonamide 1,1,4-trioxide.

The results presented here complemented the current knowledge about degradation processes of dihydralazine and hydrochlorothiazide. These data may be the starting point for further studies on new degradation products in terms of their potential toxicity and then, for qualifying them as new related substances in pharmacopoeial monographs. These data may also serve as a starting point for designing new two-component formulations. 

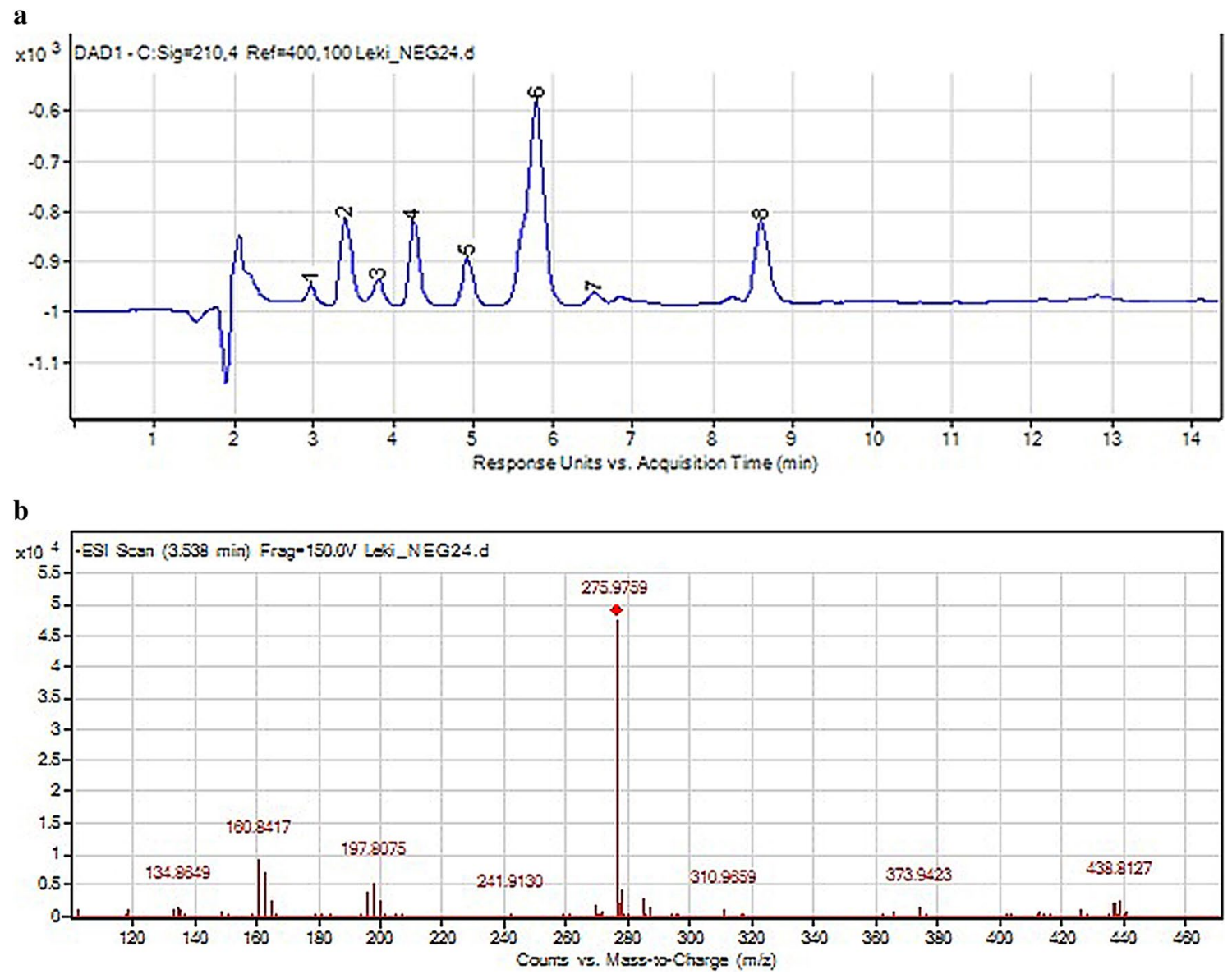

Fig. 12 a Chromatogram DAD of hydrochlorothiazide (7) and degradation products of hydrochlorothiazide and dihydralazine (1-6, 8) in the mixture under UV/Vis light. b Negative ion ESI LC/MS of degradation product of hydrochlorothiazide (2): CID off set $10 \mathrm{~V}$

Fig. 13 Proposed photodegradation pathway of hydrochlorothiazide in presence of dihydralazine<smiles>NS(=O)(=O)c1cc2c(cc1Cl)NCNS2(=O)=O</smiles><smiles>C=C</smiles>

$\mathrm{C}_{7} \mathrm{H}_{7} \mathrm{ClN}_{3} \mathrm{O}_{4} \mathrm{~S}_{2}^{-}$

Exact Mass: 295,96<smiles></smiles>

$\mathrm{C}_{7} \mathrm{H}_{6} \mathrm{~N}_{3} \mathrm{O}_{5} \mathrm{~S}_{2}^{-}$

Exact Mass: 275,98

\section{Compliance with Ethical Standards}

Conflict of Interest The authors declare that they have no conflict of interest.

Ethical Approval This article does not contain any studies with human participants or animals performed by any of the authors.

Open Access This article is distributed under the terms of the Creative Commons Attribution 4.0 International License (http://creat ivecommons.org/licenses/by/4.0/), which permits unrestricted use, distribution, and reproduction in any medium, provided you give appropriate credit to the original author(s) and the source, provide a link to the Creative Commons license, and indicate if changes were made.

\section{References}

1. Wu Y, Hu Y, Tang X, He L, Ren T, Tao Q, Qin X, Sun N, Wang H, Cao W, Wu T, Zhan S, Wang J, Chen W, Li L (2011) Longterm efficacy and tolerability of a fixed-dose combination of 
antihypertensive agents: an open-label surveillance study in China. Clin Drug Invest 31:769-777

2. European Pharmacopeia 9th edn. (2016) Council of Europe, Strasbourg

3. Raul SK, Ravi Kumar BV, Pattnaik AK, Rao NN (2013) A RPHPLC method development and validation for the estimation of dihydralazine in bulk and pharmaceutical dosage forms. Int J Pharm 3:116-121

4. Che BQ (2004) Determination of five components in compound hypotensive tablet by HPLC. Acta Pharm Sin 39:618-620

5. Jin PF, Kuang YT, Zou D, Hu X, Jiang WQ, Wu XJ (2011) Simultaneous determination of three active ingredients in compound hypotensive tablets by HPLC. Chin Pharm J 46:152-155

6. Ali FA (2015) Quantitative analysis of hydrochlorothiazide and its determination in a pharmaceutical preparation by HPLC. Pharm Chem J 48:845-849

7. Nataraj KS, Badrud D, Kesinath RK, Kiran D (2011) Estimation of hydrochlorothiazide in pure and pharmaceutical dosage forms by RP-HPLC. J Chem Pharm Sci 4:132-134

8. Mali AD, More UB (2016) Development and validation of RPHPLC method for simultaneous estimation of impurities from olmesartan medoxomil and hydrochlorothiazide tablet. Int $\mathbf{J}$ Pharm Pharm Sci 8:45-48

9. Harikrishnan N, Vijaya Vara Prasad M, Mohamied AS, Prabahar KK (2016) Method development and validation for assay of candesartan cilexetil and hydrochlorothiazide in tablet dosage form by RP-HPLC. Int J Res Pharm Sci 7:75-81

10. Smajić M, Vujić Z, Mulavdić N, Brborić J (2013) An improved HPLC method for simultaneous analysis of losartan potassium and hydrochlorothiazide with the aid of a chemometric protocol. Chromatographia 76:419-425

11. Vidyadhara S, Rao BV, Tejaswi K, Rani AL (2014) Analytical method development and validation for simultaneous estimation of enalapril maleate and hydrochlorothiazide by RP-HPLC. Der Pharm Chem 6:217-223

12. Maslarska V, Peikova L, Tsvetkova B (2013) RP-HPLC method for the simultaneous determination of lisinopril and hydrochlorothiazide in pharmaceutical formulation. Int J Pharm Sci Rev Res 22:253-256

13. Sahoo S, Panda PK, Mishra SK (2012) HPLC method development for simultaneous estimation of hydrochlorothiazide and perindropril in tablet dosage form. Asian J Pharm Clin Res 5:136-138

14. Bozal B, Gumustas M, Dogan-Topal B, Uslu B, Ozkan SA (2013) Fully validated simultaneous determination of bisoprolol fumarate and hydrochlorothiazide in their dosage forms using different voltammetric, chromatographic and spectrophotometric analytical methods. J AOAC Int 96:42-51

15. Pencheva I, Peikova L, Tzvetkova B (2013) Analytical study of UV-spectrophotometric and HPLC methods for simultaneously determination of metoprolol and hydrochlorothiazide in fixed dosage combinations. J Chem Pharm Res 5:104-108

16. Younes KM (2014) Spectrophotometric and chromatographic methods for the simultaneous determination of carvedilol and hydrochlorothiazide in their pharmaceutical formulation. Int $\mathbf{J}$ Pharm Pharm Sci 6:362-368

17. Vyankatrao GD, Omprakash B, Anil KA (2015) Method development and validation of amlodipine besylate and hydrochlorothiazide in their bulk and combined dosage form. Der Pharm Lett 7:220-224

18. Tsvetkova BG, Peikova LP (2013) Development and validation of RP-HPLC method for simultaneous determination of amlodipine besylate and hydrochlorothiazide in pharmaceutical dosage form. J Chem Pharm Res 5:271-275
19. Bhagwate S, Gaikwad NJ (2013) Stability indicating HPLC method for the determination of hydrochlorothiazide in pharmaceutical dosage form. J Appl Pharm Sci 3:88-92

20. Shaalan RA, Belal TS, El Yazbi FA, Elonsy SM (2017) Validated stability-indicating HPLC-DAD method of analysis for the antihypertensive triple mixture of amlodipine besylate, valsartan and hydrochlorothiazide in their tablets. Arab J Chem 10:1381-1394

21. Karvelis D, Kalogria E, Panderi I (2014) A stability-indicating HPLC method for the quantification of aliskiren and hydrochlorothiazide in a pharmaceutical formulation. J AOAC Int 97:1519-1525

22. Belal TS, Shaalan RA, El Yazbi FA, Elonsy SM (2013) Validated stability-indicating HPLC-DAD determination of the antihypertensive binary mixture of carvedilol and hydrochlorothiazide in tablet dosage forms. Chromatographia 76:1707-1720

23. Peikova L, Pencheva I, Tzvetkova B (2013) Chemical stabilityindicating HPLC study of fixed-dosage combination containing metoprolol tartrate and hydrochlorothiazide. J Chem Pharm Res 5:132-140

24. Rama Mohana Reddy M, Praveen Kumar A, Krishna Reddy V, Wasimul Haque S (2012) Stability-indicating HPLC method for simultaneous estimation of low level impurities of telmisartan and hydrochlorothiazide in tablet dosage forms. Int J Pharm Pharm Sci 4:497-504

25. Rane DS, Chaskar PK, Doshi GM, Mulgund SV, Jain KS (2013) Development and validation of stability indicating RP-HPLC method for simultaneous determination of telmisartan and hydrochlorothiazide from their combination drug product. Der Pharm Lett 5:27-134

26. Kharoaf M, Malkieh N, Abualhasan M, Shubitah R, Jaradat N, Zaid AN (2012) Tablet formulation and development of a validated stability indicating hplc method for quantification of valsartan and hydrochlorothiazide combination. Int J Pharm Pharm Sci 4:284-290

27. Mahajan AA, Thaker AK, Mohanraj K (2012) LC, LC-MS/MS studies for the identification and characterization of degradation products of hydrochlorothiazide and establishment of mechanistic approach towards degradation. J Braz Chem Soc 23:445-452

28. Patil AS, Sait SS, Deshamukh A, Deshpande G (2015) An improved validated HPLC method for separation of metoprolol and hydrochlorothiazide impurities in metoprolol and hydrochlorothiazide tablets. Der Pharm Lett 7:183-190

29. Mhaske RA, Garole DJ, Mhaske AA, Sahasrabudhe S (2012) RP-HPLC method for simultaneous determination of amlodipine besylate, valsartan, telmisartan, hydrochlorothiazide and chlorthalidone: application to commercially available drug products. Int J Pharm Sci 3:141-149

30. Aswini GL, Dachinamoorthy D, Seshagiri Rao JVLN. (2015) A sensitive validated stability indicating RP-HPLC method for simultaneous estimation of losartan, ramipril and hydrochlorothiazide in bulk and tablet dosage form with forced degradation studies. Int J Pharm Sci Rev Res 31:40-45

31. Kalyani K, Anuradha V, Vidyadhara S, Sasidhar RLC, Ganesh Kumar TNV (2016) A stability indicating RP-HPLC for the simultaneous estimation of hydrochlorothiazide, amlodipine besylate and telemisartan in bulk and pharmaceutical dosage form. Orient J Chem 32:1631-1637

32. Shakya AK (2016) Development and validation of a stabilityindicating liquid chromatographic method for determination of valsartan and hydrochlorothiazide using quality by design. Orient J Chem 32:777-788

33. Kotthi Reddy K, Rama Devi B (2015) Stability indicating RPHPLC method development and validation for the simultaneous estimation of candesartan cilexetil and hydrochlorothiazide in bulk and tablet dosage form. Der Pharm Lett 7:114-121 
34. Shakya AK (2015) HPLC-PDA determination of losartan potassium and hydrochlorothiazide using design of experiments. Jordan J Pharm Sci 8:153-171

35. Napa D, Sockalingam A (2014) Validated liquid chromatographic method for the estimation of antihypertensive mixture in pharmaceutical dosage form. World J Pharm Pharm Sci 3:1916-1927

36. Madhukar A, Kannappan N, Mahendra Kumar CB (2015) Analytical method development and validation for the determination of hydrochlorothiazide, amlodipine besylate and telmisartan hydrochloride in multicomponent tablet dosage form and in biorelevant media (FaSSIF) by RP-HPLC techniques. Int J Pharm Pharm Sci $7: 218-225$

37. Rekulapally VK, Rao VU (2014) Stability indicating RP-HPLC method development and validation for simultaneous estimation of aliskiren, amlodipine and hydrochlorothiazide in tablet dosage form. Int J Pharm Pharm Sci 6:724-730

38. Paszun SK, Stanisz BJ, Gradowska A (2013) Cilazapril stability in the presence of hydrochlorothiazide in model mixtures and fixed dose combination. Acta Pol Pharm 70:1079-1085

39. ICH Thopic Q1B Photostability Testing of New Active Substances and Medicinal Products (2006) EMEA. http://www.ema.europ a.eu/docs/en_GB/document_library/Scientific_guideline/2009/09/ WC500002647.pdf. Accessed 14 Mar 2018

40. De Luca M, Ioele G, Mas S, Tauler R, Ragno G (2012) A study of $\mathrm{pH}$-dependent photodegradation of amiloride by a multivariate curve resolution approach to combined kinetic and acid-base titration UV data. Analyst 137:5428-5435 